\title{
Correction to: First COVID-19 infections in the Philippines: a case report
}

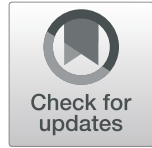

Edna M. Edrada', Edmundo B. Lopez', Jose Benito Villarama', Eumelia P. Salva Villarama', Bren F. Dagoc', Chris Smith ${ }^{2,3^{*}}$, Ana Ria Sayo ${ }^{1}$, Jeffrey A. Verona', Jamie Trifalgar-Arches ${ }^{1}$, Jezreel Lazaro ${ }^{1}$, Ellen Grace M. Balinas ${ }^{1}$, Elizabeth Freda O. Telan', Lynsil Roy', Myvie Galon', Carl Hill N. Florida', Tatsuya Ukawa², Annavi Marie G. Villanueva ${ }^{2}$, Nobuo Saito ${ }^{4}$, Jean Raphael Nepomuceno ${ }^{2}$, Koya Ariyoshi ${ }^{5}$, Celia Carlos ${ }^{6}$, Amalea Dulcene Nicolasora ${ }^{6}$ and Rontgene M. Solante ${ }^{1}$

\section{Correction to: Trop Med Health 48, 21 (2020) https://doi.org/10.1186/s41182-020-00203-0}

In the original publication of this article [1], the authors identified an error in the author name of Annavi Marie G. Villanueva.

The incorrect author name is: Annavi Marie G. Villaneuva. The correct author name is: Annavi Marie G. Villanueva.

The author group has been updated above and the original article [1] has been corrected.

\begin{abstract}
Author details
${ }^{1}$ San Lazaro Hospital, Manila, Philippines. ${ }^{2}$ School of Tropical Medicine and Global Health, Nagasaki University, Nagasaki, Japan. ${ }^{3}$ Faculty of Infectious and Tropical Diseases, London School of Hygiene and Tropical Medicine, London, UK. ${ }^{4}$ Department of Microbiology, Faculty of Medicine, Oita University, Oita, Japan. ${ }^{5}$ Institute of Tropical Medicine, Nagasaki University, Nagasaki, Japan. ${ }^{6}$ Research Institute for Tropical Medicine, Alabang, Philippines.
\end{abstract}

Published online: 07 May 2020

\section{Reference}

1. Edrada, et al. First COVID-19 infections in the Philippines: a case report. Trop Med Health. 2020;48:21.

\footnotetext{
The original article can be found online at https://doi.org/10.1186/s41182020-00203-0.

* Correspondence: christopher.smith@lshtm.ac.uk

${ }^{2}$ School of Tropical Medicine and Global Health, Nagasaki University,

Nagasaki, Japan

${ }^{3}$ Faculty of Infectious and Tropical Diseases, London School of Hygiene and

Tropical Medicine, London, UK

Full list of author information is available at the end of the article
}

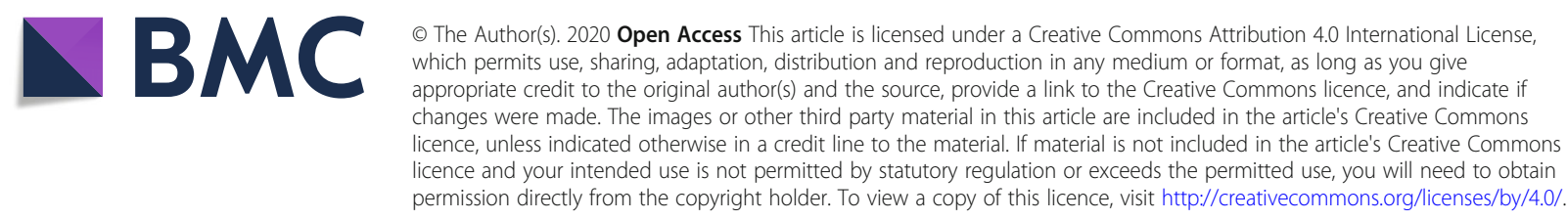

